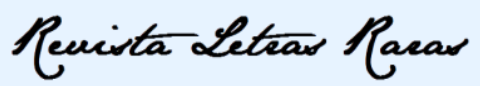

ISSN: 2317-2347 - v. 7, n. 1 (2018)

\title{
Langston Hughes e a representação do negro numa perspectiva dialógica de ensino/compreensão: uma pesquisa com alunos iniciantes do curso de Letras-Inglês / Langston Hughes and the representation of Black people from a dialogical perspective to teaching/understanding: a research study with undergraduate freshmen from the Teacher Education Program in English
}

\author{
Naiara Medeiros de Oliveira* \\ Orison Marden Bandeira de Melo Júnior ${ }^{* *}$
}

\begin{abstract}
RESUMO
Este artigo busca contribuir com os estudos relacionados ao ensino de literatura estrangeira no Brasil. Fundamentada nos pressupostos teóricos do Círculo (Bakhtin, Volóchinov, Medviédev), em especial em noções como compreensão ativo-dialógica, objetivamos analisar os dados gerados durante o minicurso "A representação do negro em contos da literatura afro-americana: uma perspectiva dialógica”, por meio de uma atividade de análise do conto "The Childhood of Jimmy" (HUGHES, 1996) no primeiro encontro (pré-teste) e no último encontro (pós-teste). Por meio da análise do pós-teste em comparação com o préteste, percebemos que os alunos, após o estudo do ensaio "O discurso no romance" (BAKHTIN, 2015) e da prática de análise de outros contos de Hughes, demonstraram compreensão (i) da relação entre texto e contexto histórico concreto, (ii) da materialidade do texto em sua natureza linguística e socioideológica e (iii) da teoria pela internalização dos conceitos estudados.

PALAVRAS-CHAVE: Ensino de literatura estrangeira; Compreensão ativo-dialógica; Literatura afroamericana; Representação do negro.
\end{abstract}

\begin{abstract}
This paper seeks to contribute to studies related to the teaching of foreign literature in Brazil. Based on the theoretical presuppositions of the Bakhtin Circle (Bakhtin, Voloshinov, Medvedev), especially on notions such as active-dialogic understanding, we aim to analyze the data generated during the minicourse "Black representation in African-American short stories: a dialogical perspective", by means of an activity of literary analysis of the short story "The Childhood of Jimmy" (HUGHES, 1996) done in the first class (pre-test) and in the last one (post-test). By analyzing the post-test in comparison with the pretest, we noticed that the participants, after the study of "Discourse in the Novel" (BAKHTIN, 2015) and the practice of analyzing other short stories by Hughes during the mini-course, demonstrated an understanding of $(i)$ the relationship between the text and the concrete historical context, (ii) the materiality of the text in its linguistic and social-ideological nature and (iii) the theory through the internalization of the concepts studied.
\end{abstract}

KEYWORDS: Foreign literature teaching; Active-dialogic understanding; African-American literature; Black representation.

\section{Introdução}

\footnotetext{
* Aluna do curso de Letras-Inglês e bolsista PIBIC da Universidade Federal do Rio Grande do Norte UFRN, Natal, Rio Grande do Norte, Brasil; naiara_may2@ hotmail.com

** Doutor em Linguística Aplicada, professor do curso de Letras-Inglês e professor permanente do Programa de Pós-graduação em Estudos da Linguagem da Universidade Federal do Rio Grande do Norte - UFRN, Natal, Rio Grande do Norte, Brasil; junori36@cchla.ufrn.br
} 


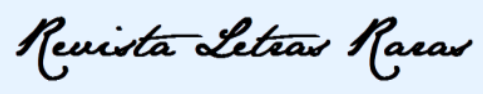

ISSN: 2317-2347 - v. 7, n. 1 (2018)

"O ensino da literatura tem estado no centro dos debates educacionais das últimas décadas", afirma Perrone-Moisés (2016, p. 75) no capítulo O ensino da Literatura. Para a autora, a literatura passou, no final do século XX, por um período de desprestígio social e cultural, tendo em vista que as demandas de mercado terminaram por considerar a literatura um produto de pouco valor mercadológico. No entanto, a autora, ao defender o ensino da literatura, utiliza, dentre outros, os seguintes argumentos: "porque ensinar literatura é ensinar a ler e, nas sociedades letradas, sem leitura não há cultura; porque a capacidade de leitura não é inata, mas adquirida [...]; porque a literatura é um instrumento de conhecimento do outro e de autoconhecimento" (PERRONE-MOISÉS, 2016, p. 80-81).

É fato que a autora está discutindo o ensino de literatura em geral e não o ensino de literatura estrangeira, o foco deste estudo. Mesmo assim, todos esses argumentos se adequam perfeitamente a este campo de pesquisa. Entretanto, gostaríamos de enfatizar o terceiro argumento, por ele coadunar com o pensamento de Bakhtin (2017a), quando discute a relação entre literatura e cultura: "a literatura é parte inseparável da cultura" (BAKHTIN, 2017a, p. 10) e a "cultura do outro só se revela em toda a plenitude e profundidade [...] aos olhos de outra cultura" (p. 18-19; grifo do autor). Essa relação de alteridade entre literatura e cultura é que se torna o elemento fundante para o estudo de literatura estrangeira.

No que tange ao ensino de literatura de língua inglesa no Brasil, Dudalski (2007), ao reconhecer a existência de poucas pesquisas nessa área, elenca alguns trabalhos apresentados no Seminário Nacional de Professores Universitários de Literaturas de Língua Inglesa em 1990 e no I Encontro Nacional sobre Ensino de Literaturas de Língua Inglesa em 2000, duas teses de doutoramento e as pesquisas de Sonia Zyngier e Laura Zuntini de Izarra, que, por vieses teóricos diferentes, trazem contribuições significativas. Entretanto, nenhum desses trabalhos parte da contribuição dos estudos do Círculo (Bakhtin, Volóchinov, Medvedev) ${ }^{1}$, o foco deste trabalho.

Melo Júnior (2015; 2016a; 2016b) busca, por meio da análise de algumas obras da literatura norte-americana contemporânea de minorias, demonstrar a riqueza analítica

\footnotetext{
${ }^{1}$ Apesar de o Círculo ser comumente chamado de Círculo de Bakhtin, ele será tratado como Círculo, ressaltando que, apesar de ter havido, como afirmam Brait e Campos (2009), "três círculos", nosso foco aqui serão os estudos de Bakhtin, Volóchinov e Medviédev.
} 


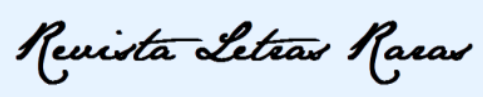

ISSN: 2317-2347 - v. 7, n. 1 (2018)

proporcionada pelos estudos do Círculo e, dessa forma, discutir as contribuições que a teoria dialógica traz ao processo de ensino e de análise do texto literário em língua inglesa. Seguindo, portanto, essa esteira teórico-analítica, este trabalho objetiva investigar essas contribuições de forma empírica, ou seja, por meio de um estudo teórico-analítico com alunos iniciantes do curso de Letras-Inglês.

Este trabalho está vinculado, portanto, ao projeto de pesquisa "Literatura estrangeira contemporânea: uma perspectiva dialógica de ensino e formação (discursiva)" e busca discutir os dados gerados durante o minicurso criado durante a vigência do projeto, intitulado A representação do negro em contos da literatura afroamericana: uma perspectiva dialógica. Esse minicurso, aprovado pelo Comitê de Ética em Pesquisa da universidade sob o número CAAE 65936917.8.0000.5537 da Plataforma Brasil, ao trabalhar contos da literatura afro-americana, especificamente da obra de Langston Hughes (1902-1967), uma figura central da Harlem Renaissance (GILYARD; WARDI, 2004)2, por meio da teoria do romance de Bakhtin (2015), buscou perceber como se deu o processo de compreensão do conto The Childhood of Jimmy (HUGHES, 1996, p. 292-294) pelos participantes do minicurso.

Diante disso, a fim de os objetivos propostos neste trabalho serem alcançados, inicialmente serão tecidas algumas considerações teóricas sobre o processo de compreensão, conforme defendido pelo Círculo e algumas noções interligadas a esse processo para que, em seguida, os elementos metodológicos da pesquisa sejam apresentados. Por fim, os dados gerados durante o minicurso serão analisados, a fim de observar a possível contribuição do dialogismo para a análise literária feita pelos alunos e a subsequente contribuição do discurso no romance (BAKHTIN, 2015) para o ensino de literatura de língua inglesa no curso de Letras.

\section{Considerações teóricas}

Um dos argumentos utilizados por Perrone-Moisés (2016) para o ensino de literatura é a possibilidade de ela capacitar o aluno a ler, que é uma habilidade

\footnotetext{
${ }^{2}$ A literatura afro-americana teve sua ascensão principalmente na época chamada Harlem Renaissance. A partir desse movimento na década de 1920, autores negros passaram não só a representar a história da escravidão e da segregação racial legalizada, mas também renovaram sua arte por meio da herança afroamericana, "uma arte negra definível e genuína, uma estética negra" (SANTOS, 2001, p. 10).
} 


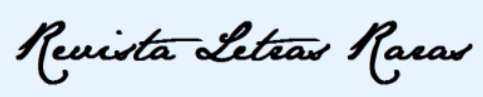

ISSN: 2317-2347 - v. 7, n. 1 (2018)

adquirida. Ao considerar o sentido proposto pela autora de que ler não é apenas uma decodificação da língua, o verbo ler pode ser substituído pelo verbo compreender, conforme proposto pelo Círculo. Dessa forma, ensinar literatura é auxiliar o aluno a compreender o texto literário.

Volóchinov (2017, p. 177), ao discutir língua, linguagem e enunciado, afirma: "para um falante, a forma linguística é importante não como um sinal constante e invariável, mas como um signo sempre mutável e flexível" (grifo do autor). Percebemos, nesta asserção, que o autor russo faz a diferença entre sinal e signo, sendo o primeiro "um objeto internamente imóvel e unitário que, na verdade, não substitui, reflete ou refrata $^{3}$ nada" (p. 178) e o segundo, aquele que "representa e substitui algo encontrado fora dele" (p. 91), ou seja, na realidade extramaterial, que é refletida e refratada na sua realidade material (p. 92). É por essa razão que o campo dos signos coincide com o campo da ideologia ${ }^{4}$, pois “onde há signo há também ideologia" e "[t]udo o que é ideológico possui significação sígnica” (p. 93; grifo do autor).

Nessa esteira, o autor relaciona o sinal à palavra dicionarizada (fora do contexto vivo e concreto de seu uso na vida) e o signo à palavra enquanto "fenômeno ideológico par excellence" (VOLÓCHINOV, 2017, p. 98; grifo do autor), que "está sempre repleta de conteúdo e de significação ideológica ou cotidiana" (VOLÓCHINOV, 2017, p. 181; grifo do autor). Para Voloshinov (1983b), diferentemente de outros objetos que se transformam em signos em estágios posteriores de sua existência, a palavra viva é, desde a sua incipiência, um fenômeno puramente ideológico, i.e., um signo ideológico.

A partir dessa diferenciação entre sinal e signo, adentramos o pensamento do Círculo no que tange ao processo de compreensão: “[a]penas um signo pode ser

\footnotetext{
${ }^{3}$ Faraco (2009, p. 50-51) explica que, para o Círculo, refratar significa que "com nossos signos nós não somente descrevemos o mundo, mas construímos - na dinâmica da história e por decorrência do caráter sempre múltiplo e heterogêneo das experiências concretas dos grupos humanos - diversas interpretações (refrações) desse mundo" (grifo do autor).

${ }^{4}$ Segundo Shukman (1983, p. 154), o Círculo utiliza o conceito de ideologia "no sentido amplo e, ao mesmo tempo, especifico da atividade sociocultural dos homens. As artes, ciências e a filosofia - todo o domínio axiológico humano, pertencem ao domínio da ideologia" (nossa tradução). [Texto original: "in the very broad and yet specific sense of human socio-cultural activity. Arts, sciences, philosophy - all the domain of human values, belong to the domain of ideology".] O próprio Vološinov (2014b, p. 1855, nota de rodapé 4; nossa tradução) define ideologia como "todo o conjunto de reflexos e refrações da realidade social e natural no cérebro humano que são expressos e fixos por meio de palavras, desenhos, diagramas ou outras formas sígnicas" [Texto original: "tutto l'insieme dei riflessi e delle rifrazioni della realtà sociale e naturale nel cervello dell'uomo espresse e fissate per mezzo di parole, disegni, diagrammi o altre forme segniche"].
} 


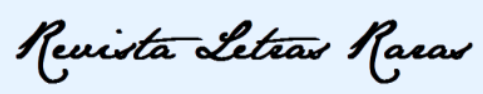

ISSN: $2317-2347$ - v. 7, n. 1 (2018)

compreendido, já o sinal é reconhecido" (VOLÓCHINOV, 2017, p. 178). Esse processo, para o autor, tem implicações, inclusive, para o processo de assimilação de uma língua estrangeira, pois “[o] ideal da assimilação da língua [estrangeira] é a incorporação do sinal pelo signo puro e do reconhecimento pela compreensão pura" (VOLÓCHINOV, 2017, p. 180). Para o autor, em métodos de ensino de línguas em que uma palavra é retirada do seu contexto de uso e anotada no caderno para ser memorizada, ela só pode ser percebida enquanto sinal. Para a sua assimilação, momento quando a língua se torna completamente língua, a palavra deve ser compreendida "na estrutura de um enunciado concreto, como um signo mutável e flexível" (VOLÓCHINOV, 2017, p. 180; nota de rodapé 37).

A necessidade de se conhecer o contexto de uso para o processo de compreensão é resultado do fato de que a palavra pode assumir qualquer função ideológica (VOLÓCHINOV, 2017); por conseguinte, só é compreendida enquanto palavra-signo "na interação social viva, no enunciado real que pode ser compreendido e avaliado tanto pelo falante quanto pelo ouvinte potencial ou real" (VOLOSHINOV, 1983b, p. 144) ${ }^{5}$. Tirá-la desse contexto ou situação concreta é reduzi-la a um sinal (objetivado e estagnado), o que é, para o autor, "um dos erros mais graves do objetivismo abstrato" (VOLÓCHINOV, 2017, p. 182), tendência do pensamento linguístico que, segundo ele, encontra, nos postulados de Saussure, o seu significado fundamental. É essa tendência que, para Bakhtin (2015, p. 63), leva à unicidade da língua, ou seja, a língua "como sistema gramatical abstrato de formas normativas, desviada das assimilações ideológicas concretas que a preenchem e da contínua formação histórica da língua viva".

Em relação ao contexto, Arán (2006) explica que Bakhtin estabelece uma diferença entre contexto próximo e remoto. O contexto próximo, ao mesmo tempo que "permanece fora de dado texto como fundo axiológico de sua percepção" (BAKHTIN, 2017b, p. 74), integra a obra como seu "necessário contexto extratextual. É como se ela fosse envolvida pela música do contexto axiológico-entonacional, no qual é interpretada e avaliada" (BAKHTIN, 2017b, p. 74). Esse contexto extraverbal de um enunciado, que

\footnotetext{
${ }^{5}$ Todas as traduções feitas neste trabalho do inglês ou do italiano são nossas.

Texto original: "in living social intercourse, in a real utterance which can be understood and evaluated not only by the speaker, but also by his potencial or actual audience".
} 


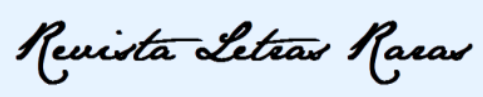

ISSN: 2317-2347 - v. 7, n. 1 (2018)

para Bakhtin é a "unidade real da comunicação discursiva" (BAKHTIN, 2016, p. 22), é, no discurso na vida, composto de três fatores: (i) um horizonte espacial comum entre interlocutores, (ii) o seu conhecimento e compreensão da situação e (iii) a sua avaliação dessa situação (VOLOSHINOV, 1983a, p. 11). A situação, para Voloshinov (1983c), é composta pelo tempo e espaço do evento enunciativo, pelo tópico ou o tema do enunciado e pela avaliação dos interlocutores sobre o evento enunciativo.

Essa situação (componente extraverbal do enunciado) não é uma força externa que influencia o enunciado de fora para dentro; pelo contrário, Voloshinov (1983a, p. 12) esclarece que "a situação penetra o enunciado como um elemento constitutivo essencial da sua estrutura de sentido" (grifo do autor) ${ }^{6}$, levando a vida não a agir sobre ou influenciar o enunciado de fora, mas a penetrá-lo do seu interior (VOLOSHINOV, 1983a, p. 18), pois "é igualmente através de enunciados concretos que a vida entra na língua" (BAKHTIN, 2016, p. 16-17). No enunciado artístico (um romance, um conto, por exemplo), Voloshinov (1983a, p. 18) determina que cabe ao autor dar uma representação verbal aos elementos situacionais da obra: “do ponto de vista pragmático do tópico, nada na obra poética pode ser deixado não dito"7. Entretanto, o autor ainda lembra que o escritor-artista, no processo criativo, não escolhe sinais (palavras dicionarizadas), mas signos verbais (palavras) do contexto da vida, onde "são formadas e impregnadas de valoração" (VOLOŠINOV, 2014a, p. 309) ${ }^{8}$. É por essa razão que Bakhtin (2015, p. 122) confirma o pensamento de Voloshinov (1983a), afirmando que "[a] prosa ficcional pressupõe uma sensação premeditada de concretude histórica e social e relatividade da palavra viva, de sua participação na formação histórica e na luta social"; adiciona que o prosador, na sua escolha lexical, elemento verbal do enunciado, "toma a palavra ainda aquecida pelo calor da luta e das hostilidades [...] e nesse estado a subordina à unidade dinâmica de seu próprio estilo" (BAKHTIN, 2015, p. 122). Nesse sentido, Voloshinov (1983b) explica que as relações de classe entram no enunciado como uma força ativa que influencia, de forma decisiva, a estrutura estilística do

\footnotetext{
${ }^{6}$ Texto original: "the situation enters into the utterance as an essential constituent part of its sense structure".

${ }^{7}$ Texto original: "If]rom the pragmatic view of the topic nothing in the poetic work can be left unspoken". $\mathrm{Na}$ tradução ao italiano desse ensaio, ponto de vista pragmático do tópico é traduzido como "ponto de vista pragmático-objetivo" (VOLOŠINOV, 2014a, p. 307; nossa tradução). Texto original: "un punto di vista pragmatico-oggettivo".

${ }^{8}$ Texto no original: "dove esse si sono formate e si sono impregnate di valutazioni".
} 


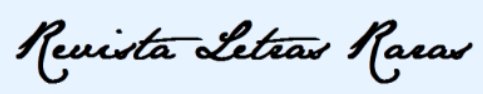

ISSN: 2317-2347 - v. 7, n. 1 (2018)

enunciado (quer literário ou não). Consequentemente, "a vida não se encontra só fora da arte, mas também nela, no seu interior, em toda a plenitude do seu peso axiológico: social, político, cognitivo ou outro que seja" (BAKHTIN, 2014, p. 33; grifo do autor).

É importante lembrarmos que a vida penetra o objeto estético por meio do material utilizado pelo criador: a língua(gem) (VOLOSHINOV, 1983d, p. 111), a palavra (BAKHTIN, 2014, p. 20). No projeto de criação do objeto estético, o artistaprosador articula conteúdo, material e forma num todo arquitetônico (BAKHTIN, 2014) e, diante do distanciamento que possui em relação à obra, orquestra todas as língua(gen)s e vozes do mundo social: “o prosador usa linguagens já povoadas de intenções sociais alheias e as obriga a servir às suas novas intenções, a servir a um segundo senhor" (BAKHTIN, 2015, p. 76-77). Diferentemente do inacabamento da vida, o objeto estético é um evento acabado, orquestrado pelo seu criador, que, ao dar forma a ele, utiliza-se do material em seu aspecto formal e discursivo. Assim como a "[a] estética da obra literária não deve passar por cima da língua linguística" (BAKHTIN, 2014, p. 52), o artista-prosador "liberta-se da língua na sua determinação linguística não ao negá-la, mas graças ao seu aperfeiçoamento imanente: o artista como que vence a língua graças ao próprio instrumento linguístico e, aperfeiçoando-a linguisticamente, obriga-a a superar a si própria. (BAKHTIN, 2014, p. 50; grifo do autor). Faraco (2011, p. 23) explica que “[a] forma do material da arte literária [...] [é] uma transposição da língua viva (situada) para outro plano axiológico, para o interior de outro enunciado concreto que está corporificando uma determinada forma arquitetônica e composicional".

Ao entendermos a obra como enunciado (BAKHTIN, 2016; VOLÓCHINOV, 2017), que é constituído de elementos verbais e não verbais e estabelece relações dialógicas com outros enunciados (próximos e remotos), é possível discutirmos, agora, o contexto remoto do enunciado (obra). Como "[t]odo enunciado é um elo na cadeia da comunicação discursiva" (BAKHTIN, 2016, p. 46-47), também “[a] obra é um elo na cadeia da comunicação discursiva (BAKHTIN, 2016, p. 34-35). Como o enunciado é "pleno de ecos e ressonâncias de outros enunciados com os quais está ligado pela identidade da esfera de comunicação discursiva" (BAKHTIN, 2016, p. 57), as obras literárias "dissolvem as fronteiras de sua época, vivem nos séculos, isto é, no grande tempo" (BAKHTIN, 2017a, p. 14; grifo do autor). É esse o contexto remoto da obra 


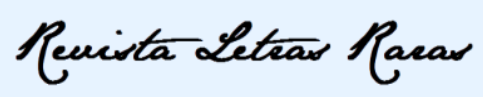

ISSN: 2317-2347 - v. 7, n. 1 (2018)

que, ao entrar no grande tempo, como um enunciado-elo, reúne os séculos passados em si mesma e se enriquece com novos significados e sentidos nas épocas futuras e distantes: "uma obra de literatura se revela antes de tudo na unidade diferenciada da cultura da época de sua criação, mas não se pode fechá-la nessa época: sua plenitude só se revela no grande tempo" (BAKHTIN, 2017a, p. 16; grifo do autor). Por conseguinte, a relação entre o contexto próximo e remoto da obra literária confirma a sua natureza de enunciado, enquanto unidade e elo da comunicação discursiva, que não só ressoa elos passados, mas também, “como a réplica do diálogo, está disposta para a resposta do outro (dos outros), para a sua ativa compreensão responsiva" (BAKHTIN, 2016, p. 34) no futuro.

É essa compreensão que nos interessa neste estudo. A partir do que foi discutido até o momento, torna-se mais fácil lermos o excerto abaixo:

\begin{abstract}
A compreensão. Desmembramento da compreensão em atos particulares. Na compreensão efetiva, real e concreta, eles se fundem indissoluvelmente em um processo único de compreensão, porém cada ato particular tem uma autonomia semântica (de conteúdo) ideal e pode ser destacado do ato empírico concreto. 1) A percepção psicofisiológica do signo físico (palavra, cor, forma espacial). 2) Sua inteiração (como conhecido ou desconhecido). A compreensão de seu significado reprodutível (geral) na língua. 3) A compreensão de seu significado em dado contexto (mais próximo e mais distante). 4) A compreensão ativo-dialógica (discussão-concordância). A inserção no contexto dialógico. O elemento valorativo na compreensão e seu grau de profundidade e de universalidade. (BAKHTIN, 2017b, p. 62-63).
\end{abstract}

Essas notas de Bakhtin (2017b) sobre compreensão resumem a discussão proposta nesta seção do artigo, tendo em vista que a compreensão parte do sinal (o seu significado reprodutível) em busca do seu sentido (significado contextualizado) e, de forma ativa, estabelece relações dialógicas no grande tempo. Voloshinov (1983a), nessa esteira, declara que o processo de análise sociológica de um objeto estético deve tomar, como ponto de partida, os elementos puramente verbais do enunciado-obra - o que Bakhtin chama de língua linguística - mas, não se confinando a esses limites puramente verbais, já que a palavra não é escolhida pelo autor-criador como sinal, mas como signo, leva o leitor/analista para além dessa clausura material-verbal, aspirando a uma 


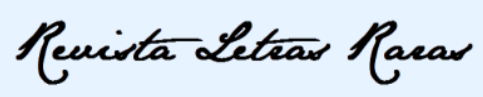

ISSN: $2317-2347$ - v. 7, n. 1 (2018)

significação social (BAKHTIN, 2015). Percebemos, portanto, a confluência entre o processo de compreensão e o de análise sociológica propostos pelos autores.

Como "toda compreensão plena real é ativamente responsiva", já que é "prenhe de resposta" (BAKHTIN, 2016, p. 25), a compreensão de uma obra literária é uma "compreensão responsiva de efeito retardado: cedo ou tarde, o que foi ouvido e ativamente entendido responde nos discursos subsequentes ou no comportamento do ouvinte" (BAKHTIN, 2016, p. 25), ocupando esse uma posição ativo-responsiva diante do enunciado lido/ouvido: concorda ou discorda dele de forma parcial ou total, completa-o, aplica-o, etc., ou seja, responde a ele. Para o autor russo, o esquema proposto por Saussure, segundo o qual a produção (fala) é ativa e a recepção (escuta/compreensão) é passiva, "deforma o quadro real da comunicação discursiva" (BAKHTIN, 2016, p. 27), pois enfraquece o papel do ouvinte/leitor no processo de compreensão ativo-dialógico. Bakhtin (2017c) outorga ao leitor um papel tão ativo que define as duas tarefas que tem no processo de compreensão de uma obra: primeira tarefa: "compreender uma obra da mesma maneira como a compreendeu o próprio autor sem sair dos limites da compreensão dele"; segunda tarefa: "utilizar a sua distância [...] temporal e cultural" nesse processo. (BAKHTIN, 2017c, p. 40). Enquanto a primeira exige "a mobilização de um imenso material" devido a contextos socioculturais e históricos diferentes, em especial quando se busca a compreensão de uma obra literária estrangeira, a segunda exige a distância do leitor/ intérprete "no tempo, no espaço, na cultura - em relação àquilo que ele pretende interpretar de forma criadora. [...] A distância é a alavanca mais poderosa da interpretação" (BAKHTIN, 2017a, p. 18). Bezerra (2017) explica que, por meio do distanciamento, o leitor, a partir da sua posição espacial, temporal e cultural, ao ler e compreender as obras (do passado) e estabelecer com elas um diálogo (compreensão ativo dialógica), "amplia a atualiza o valor simbólico que elas irradiam”. (BEZERRA, 2012, p. 92).

É essa compreensão e esse "encontro dialógico de duas culturas" (BAKHTIN, 2017a, p. 19) que se busca no processo de ensino de literatura estrangeira no Brasil. Foi essa a força motriz que norteou o estabelecimento dos objetivos e a execução deste estudo, que será explicitado na próxima seção. 


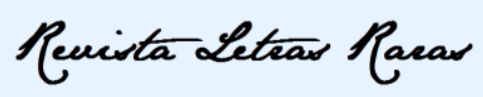

ISSN: $2317-2347$ - v. 7, n. 1 (2018)

\section{Detalhamento do estudo}

Como mencionado na Introdução, o objetivo principal desta pesquisa foi desenvolver, teórico-metodologicamente, com alunos de Letras-Inglês, uma proposta dialógica de ensino de literatura estrangeira, buscando a formação profissional e discursiva desses alunos. Metodologicamente, ele foi realizado em três fases, sendo a primeira para o estudo de obras do Círculo voltados ao discurso no romance e ao levantamento de autores e obras da literatura afro-americana. A segunda fase voltou-se à criação e execução do minicurso $A$ representação do negro em contos da literatura afro-americana: uma perspectiva dialógica, e a terceira concentrou-se na análise dos dados gerados durante o minicurso.

Esse minicurso foi oferecido a alunos iniciantes do curso de Letras-inglês, que ainda não conheciam os estudos do Círculo. Para tal, convidamos todos os alunos iniciantes de 2017 a participar do minicurso e, consequentemente, da pesquisa. Aos interessados, enviamos um formulário de inscrição, no qual deveriam declarar o seu nível de conhecimento do inglês (os contos seriam lidos no original) e o conhecimento prévio dos estudos do Círculo. Com base nesses dados, estabelecemos os critérios de seleção dos alunos: alunos com conhecimento necessário da língua inglesa para a leitura de textos em inglês e sem conhecimento dos estudos do Círculo. Dessa forma, sete alunos do primeiro semestre participaram do minicurso entre os dias 20 de abril de 2017 a 08 de junho de 2017. É importante destacar que outros três alunos também participaram, mas os seus dados não foram utilizados na análise por não atenderem, total ou parcialmente, a esses critérios.

O minicurso teve a duração de oito encontros, totalizando 20 horas. No primeiro encontro, apresentamos a pesquisa aos alunos, lemos o Termo de Consentimento Livre e Esclarecido (TCLE) com eles e obtivemos as suas assinaturas. Sem nenhuma discussão teórica, entregamos-lhes o conto The Childhood of Jimmy (HUGHES, 1996, p. 292-294) e uma atividade de análise, com duas questões apenas: a primeira pedia um breve resumo do enredo do conto e a segunda questionava quais discursos (elementos sociais, históricos, ideológicos, religiosos, entre outros) conseguiam perceber no conto que representassem subjetivamente o negro americano. Essa atividade respondida pelos 


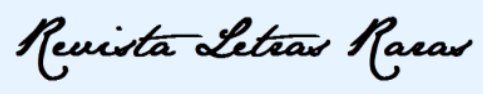

ISSN: 2317-2347 - v. 7, n. 1 (2018)

alunos foi considerada o nosso pré-teste. Ela seria feita novamente no final do minicurso como pós-teste.

Nos demais encontros, foi feita a leitura e discussão dos quatro primeiros capítulos do ensaio $O$ discurso no Romance (BAKHTIN, 2015) e a análise de outros contos de Hughes (1996): On the Road (p. 90-94), Breakfast in Virginia (p. 165-167), Thank You, M'am (p. 223-226) e Sailor Ashore (p. 185-189). Esses contos foram selecionados a partir de dois critérios: conteúdo ideológico mais perceptível, tendo em vista que os alunos eram iniciantes no curso, e a sua extensão, pois, para fazermos as atividades durante os encontros, eles não poderiam ser tão extensos. Ademais, discutimos, conforme nos eram exigidos pelos contos, que buscavam significação social (BAKHTIN, 2015), temas relacionados à história dos negros nos Estados Unidos, como o período Jim Crow(ism) (a segregação legalizada) ${ }^{9}$, a linha de cor, linchamentos, etc.

Após a fase de discussões que intercalava a teoria e análise dos contos, no último encontro, foi aplicado o pós-teste: a atividade de análise do conto The Childhood of Jimmy, realizada no primeiro encontro.

Por meio da análise do pós-teste em relação ao pré-teste, buscamos perceber se os alunos se aprofundaram em suas análises, mostrando uma compreensão ativodialógica do conto. Em outras palavras, procuramos identificar se havia discursos explicitados pelos alunos no pós-teste que não foram percebidos no primeiro momento, apontando para uma possível contribuição dos estudos do Círculo para o ensino de literatura estrangeira no Brasil.

\section{Resultados e discussões}

Como apresentado na seção anterior, os dados a serem discutidos compreendem uma atividade de análise do conto The Childhood of Jimmy (HUGHES, 1996) feita no primeiro encontro (pré-teste) e no último encontro (pós-teste) por sete alunos iniciantes do curso de Letras-Inglês no primeiro semestre de 2017. Essa atividade buscava a

\footnotetext{
${ }^{9}$ Vários autores apresentam e discutem esse período da história dos negros americanos chamado de Jim Crow(ism), período de segregação racial legalizada. Entre eles, destacamos Michael J. Klarman, autor da obra From Jim Crow to civil rights : the Supreme Court and the struggle for racial equality (2004).
} 


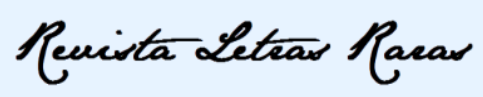

ISSN: 2317-2347 - v. 7, n. 1 (2018)

compreensão ativo-dialógica do aluno em relação ao enredo do conto e aos discursos que preenchem esse enunciado concreto do seu interior (VOLOSHINOV, 1983a).

Em relação à primeira questão, é importante explicar que Bakhtin (2015), ao discutir o falante do romance, declara que não só a palavra desse falante é preenchida ideologicamente (um ideologema), pois "exatamente como ideologema [é] que a palavra se torna objeto de representação no romance" (p. 125), como a própria ação do herói é "ideologicamente destacada: ele vive e age em seu próprio universo ideológico [...], tem sua própria apreensão do mundo (Gesinnung), que se materializa na ação e na palavra” (p. 127). Entretanto, Bakhtin não deixa o enredo de fora dessa discussão, pois, para ele, "[o] enredo romanesco deve organizar a revelação das linguagens sociais e ideologias, sua exposição e sua experimentação [...]. Em suma, o enredo romanesco serve para representar os falantes e seus universos ideológicos" (BAKHTIN, 2015, p. 164). Dessa forma, investigar a compreensão ativo-dialógica do aluno a respeito do enredo é muito mais do que apenas investigar o seu conhecimento da língua (sem descartá-lo, obviamente): é buscar examinar a relação que ele estabelece entre o enredo e o mundo socioideológico representado no conto.

É importante esclarecer, ainda, que o conto The Childhood of Jimmy (HUGHES, 1996), publicado pela primeira vez em $1927^{10}$, é um pequeno conto dividido em seis seções, chamadas de figuras/imagens (pictures), como está presente no subtítulo: Six Pictures in the Head of a Negro Boy [Seis figuras/imagens na cabeça de um menino negro] (p. 292). As seis figuras/imagens são: The Town [A cidade] (p. 292); The School [A escola] (p. 292); The Difference [A diferença] (p. 292-293); The Soul [A alma] (p. 293); The Body [O corpo] (p. 293) e Death [Morte] (p. 293-294). Cada seção é formada de um parágrafo somente e não tem, necessariamente, uma conexão linear-temporal entre elas. De forma generalizada, na primeira seção, lemos a informação de que o narrador Jimmy mora com sua tia em uma cidade onde há duas igrejas. Na segunda seção, ele apresenta a escola segregada e a sua experiência, no terceiro ano escolar, de estar em uma sala com alunos brancos e uma professora branca. Na terceira, Jimmy conta a experiência de seu amigo chamá-lo de nigger. Na quarta, ele descreve a sua

10 O conto foi primeiramente publicado pela revista The Crisis, fundada em 1910 pelo sociólogo, historiador, ativista, autor e editor afro-americano W.E.B. Du Bois (https://www.thecrisismagazine.com/). A revista é a publicação oficial da NAACP (National Association for the Advancement of Colored People), fundada em 1909. 


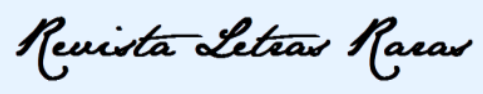

ISSN: 2317-2347 - v. 7, n. 1 (2018)

conversão, apesar do seu reconhecimento de não amar a Deus. Na quinta, Jimmy narra o fato de Clarence, um vizinho, ter engravidado uma garota, ser preso e ter de casar com ela. Na última seção, o narrador menciona a morte da sua avó e explica que, como consequência, não foi trabalhar na venda de jornais. Finalmente, afirma que foi morar em outra cidade e começou a trabalhar em um hotel.

Percebemos que, no pré-teste, todos os participantes apresentaram, como pedia a questão, um resumo do enredo do conto. É importante enfatizar que as diferenças entre esses resumos no pré-teste ficaram bem distribuídas em relação à quantidade de participantes. Desse modo, a maioria dos participantes ora apresentou o enredo de forma bastante detalhada, já citando elementos discursivos (mesmo superficialmente) que podiam ser percebidos com mais facilidade, como a segregação vivida pelo personagem na escola e a imposição da religião, ora trouxe um resumo que também tecia detalhes sobre as principais passagens do texto, mas preocupando-se em dividir o texto em suas respectivas seções e atentando para questões literárias, como o tipo de narrador, a forma e divisão do texto em imagens ou episódios. Apenas um aluno fez um resumo sucinto, que apresentava apenas a ideia da narrativa sem muitos detalhes.

Já no pós-teste, todos os participantes também atenderam ao que era esperado na questão, resumindo o enredo do conto. No entanto, percebemos que houve uma expansão significativa com relação ao tamanho dos textos, uma vez que os alunos fizeram resumos muito mais detalhados, de modo a trazer informações mais pontuais e um aprofundamento na descrição dos eventos. Concomitantemente a essas descrições, a maioria também introduziu mais elementos discursivos ou citou os mesmos que já haviam identificado no pré-teste, porém de forma mais consistente. Apenas um participante manteve o resumo objetivo, sem muita diferença em relação ao pré-teste, não mencionando elementos discursivos. A tabela abaixo apresenta, como exemplo, o início da resposta à primeira questão do pré-teste e do pós-teste de um aluno ${ }^{11}$.

Tabela 1 - Resumo do Conto (primeira questão)

\begin{tabular}{|l|l|}
\hline Pré-teste & Pós-teste \\
\hline
\end{tabular}

11 Por questões éticas de confidencialidade, não especificaremos os nomes dos alunos, mas generalizaremos pelo masculino (aluno) ao apresentarmos e analisarmos excertos das suas respostas ao longo dessa seção. 


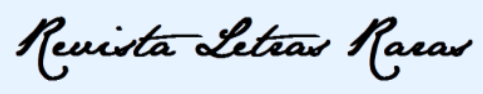

ISSN: 2317-2347 - v. 7, n. 1 (2018)

O conto narra, de certa forma, o período da infância de um garoto negro nos EUA, apesar de utilizar seis imagens fixas para garantir essa progressão.
O conto trabalha a progressão da vida - e da construção da identidade - de um menino negro. Não necessariamente consciente de como a identidade negra, como povo e como comunidade, como parte de uma sociedade segregada, mas necessariamente permeada por essas questões. O conto é dividido em seis imagens estáticas que sinalizam o progredir da vida e da identidade, mas também a paralisia e os limites de mudança e crescimento do menino negro.

Como é possível perceber na resposta do aluno, a sua compreensão ativodialógica (BAKHTIN, 2017b) do enredo do conto, no pós-teste, levou-o a responder ao conto a partir das conexões que estabeleceu entre o conto, enquanto elo na cadeia da comunicação discursiva (BAKHTIN, 2016), e o contexto do negro na "sociedade segregada", resultado do Jim Crowism, e da "construção da identidade" a partir desses discursos de segregação impostos à sua comunidade. A relação entre enredo e ideologia (BAKHTIN, 2015), entre Jimmy e seu universo ideológico, também é trazida à tona pelo aluno, que percebe como a forma ("o conto é dividido em seis imagens estáticas") "é a expressão da relação axiológica ativa do autor criador e do indivíduo que percebe (cocriador da forma) com o conteúdo" (BAKHTIN, 2014, p. 59): as seis imagens estáticas (forma) com "a paralisia e os limites de mudança e crescimento do menino negro" (conteúdo).

$\mathrm{Na}$ segunda questão, relacionada aos discursos que representavam o negro americano, os alunos também identificaram alguns elementos discursivos no pré-teste; no entanto, suas análises estavam bastante atreladas a fatos do enredo, apresentando apenas os elementos discursivos mais evidentes, como o discurso racista e a segregação vivida pela personagem Jimmy, mas ainda de forma muito genérica. A maioria citou apenas questões relacionadas ao preconceito racial e à imposição da religião, remetendo-se a passagens do texto.

Por meio da análise do pós-teste em comparação com o pré-teste, percebemos que as questões discursivas no conto foram apresentadas de forma mais pontual e substancial no segundo momento. Para facilitar a nossa exposição das respostas dos 


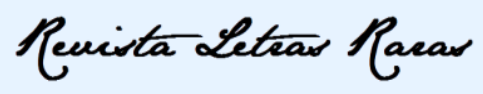

ISSN: 2317-2347 - v. 7, n. 1 (2018)

alunos, apontaremos exemplos de algumas respostas a partir de categorias analíticas de compreensão suscitados pelos dados: a compreensão do contexto histórico demandado pelo conto, a compreensão da materialidade (a palavra em seu aspecto linguístico e socioideológico) e a compreensão da teoria pela internalização dos conceitos.

a. Compreensão do contexto histórico concreto

Tabela 2 - Discursos Socioideológicos no Conto (segunda questão)

\begin{tabular}{|l|l|}
\hline Pré-teste & Pós-teste \\
\hline $\begin{array}{l}\text { Há a nítida separação dos negros e dos } \\
\text { brancos. As crianças não são crianças } \\
\text { quaisquer - elas são brancas ou "de cor". }\end{array}$ & $\begin{array}{l}\text { Na segunda imagem - "The school" - há o } \\
\text { preconceito racial, certamente legalizado, } \\
\text { talvez seja o Jim Crow. Os alunos são } \\
\text { separados por cor/raça e suas professoras } \\
\text { A escola é segregada de acordo com o tom } \\
\text { da pele; no entanto, ambas as professoras } \\
\text { - a negra e a branca - parecem não gostar } \\
\text { de lá. }\end{array}$ \\
\hline
\end{tabular}

Percebemos, neste excerto, o aprofundamento do aluno ao relatar os discursos relacionados à segregação racial, apresentando contextos históricos concretos ("preconceito racial, certamente legalizado"), como a era Jim Crow. Pacheco (1983) explica que as leis segregacionistas foram aprovadas a partir de 1896 e legitimavam as práticas de segregação racial, negando aos negros o direito de compartilhar as mesmas esferas sociais que brancos, como a escola, transporte público, áreas de lazer e até mesmo o casamento inter-racial.

Para Franklin e Moss Jr. (1994), na primeira metade do século XX, a maioria das crianças negras frequentava a escola por um curto prazo, não concluindo o ensino fundamental (elementary school). As escolas tinham condições precárias, sem capacidade para receber as crianças, sem contar com o mínimo de recursos em todos os níveis da educação básica. E ainda, com a evasão, as escolas iam sendo fechadas, enquanto as escolas para brancos permaneciam em perfeito funcionamento, visto que a verba era diferenciada para ambas. Ou seja, essa sociedade refratada no conto analisado pelos participantes garantia que negros não tivessem acesso às mesmas oportunidades 


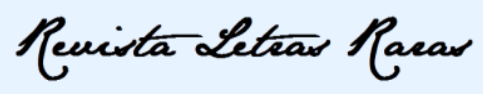

ISSN: 2317-2347 - v. 7, n. 1 (2018)

educacionais que os brancos e, consequentemente, jamais poderiam ocupar as mesmas posições sociais.

Ao buscar o contexto sociohistórico concreto demandado pelo texto ("talvez seja o Jim Crow"), o aluno procura realizar a primeira tarefa da compreensão preconizada por Bakhtin (2017c), ou seja, de compreendê-la como a compreendeu o seu autor. Como a publicação do conto se deu, pela primeira vez, em 1927, período marcado pelas leis da segregação legalizada nos Estados Unidos, o aluno, em sua análise sociológica, não ficou confinado aos limites do texto-enunciado, mas, a partir dele, como enunciado-elo (BAKHTIN, 2016), estabeleceu relações dialógicas com o seu contexto sociohistórico real e concreto de produção e recepção (VOLOSHINOV, 1983a).

b. Compreensão da materialidade (a palavra e sua natureza linguística e socioideológica)

Tabela 3 - Discursos Socioideológicos no Conto (segunda questão)

\begin{tabular}{|l|l|}
\hline Pré-teste & Pós-teste \\
\hline A cidade é descrita como um lugar que & A prova disso, no texto, está no fato deles \\
atende às necessidades. Nela há lojas, duas & viverem em uma cidade segregada, na \\
igrejas e pessoas negras. "The town" deixa & qual os negros se referem como colored e \\
exposta uma necessidade de de & os brancos os agridem com nigger. A \\
reconhecimento e de, talvez, criação de de & $\begin{array}{l}\text { cidade mesmo pequena possui duas } \\
\text { espaço seguro. }\end{array}$ \\
& $\begin{array}{l}\text { igrejas, fato destacado na última frase do } \\
\text { primeiro conto [primeira seção], e a escola } \\
\text { é segregada. }\end{array}$ \\
\hline
\end{tabular}

É interessante vermos a grande mudança na descrição da cidade (the town) no pré-teste e no pós-teste. No primeiro momento, apesar de o aluno apontar para um local geográfico em que se tem a necessidade de segurança, afirma que a cidade consegue atender às necessidades de seus habitantes devido às lojas e às duas igrejas que nela existem. No pós-teste, fica muito mais evidente a ideia da segregação tanto em termos geográficos ("a cidade mesmo pequena possui duas igrejas"; "a escola é segregada") quanto em termos linguísticos ("colored" e "nigger"). Assim como em outras atividades analisadas, é possível percebermos que o processo de compressão deixa de ser 


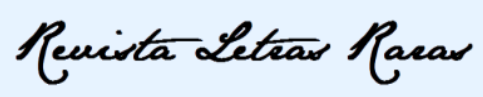

ISSN: 2317-2347 - v. 7, n. 1 (2018)

generalizado e passa a ser pontual, com a utilização de palavras utilizadas pelo próprio narrador. Trata-se da metodologia da análise sociológica de Voloshinov (1983a) e da compreensão de Bakhtin (2017b). É importante percebermos, nesse processo analítico, que, na oração "os negros se referem como colored e os brancos os agridem com nigger", as palavras colored e nigger não são percebidas como significado reprodutível (sinal), mas como significado no contexto próximo e distante (BAKHTIN, 2017b), como signo ideológico (VOLÓCHINOV, 2017), levando o aluno, na sua compreensão responsiva (BAKHTIN, 2016), a relacionar a palavra nigger com agressão. Percebendo a língua como um "sistema de avaliações sociais" (MEDVIÉDEV, 2012, p. 186) e a palavra como "o medium mais apurado e sensível da comunicação social" (VOLÓCHINOV, 2017, p. 99), o aluno relaciona a palavra nigger com o valor da agressão.

Para compreendermos a palavra nigger em sua relação axiológica com a violência, precisamos recorrer à explicação da palavra feita por Bankole (2005). Para a autora, por volta do século XVIII, o termo negro passou a ser usado por angloamericanos ao se referirem a todas as pessoas de ascendência africana, considerados como a divisão mais inferior da raça humana, sendo os caucasianos os primeiros, os mongoloides os segundos e os negroides os terceiros. Além disso, a partir de negro, cria-se o termo pejorativo nigger, um conceito "imbuído da noção de inferioridade racial, tornando-se sinônimo da palavra escravo" (BANKOLE, 2005, p. 370; grifo do autor) $^{12}$. É essa agressão/violência a que a compreensão ativo-dialógica do aluno se refere: o aluno, como leitor do enunciado, responde a ele ao confirmar o uso histórico da palavra nigger (BANKOLE, 2005) e lhe conferir, axiologicamente, o valor negativo de agressão.

c. A compreensão da teoria pela internalização dos conceitos.

Tabela 4 - Discursos Socioideológicos no Conto (segunda questão)

\begin{tabular}{|l|l|}
\hline Pré-teste & Pós-teste \\
\hline
\end{tabular}

${ }^{12}$ Texto original: "imbued with notions of racial inferiority and was made synonymous with the word slave". 


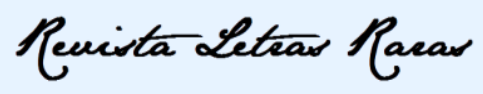

ISSN: 2317-2347 - v. 7, n. 1 (2018)

\begin{tabular}{|l|l|}
\hline $\begin{array}{l}\text { Alguns aspectos encontrados no conto que } \\
\text { representam o negro americano são: [...]. }\end{array}$ & $\begin{array}{l}\text { As vozes sociais que estão presentes no } \\
\text { texto têm uma carga histórica de discursos } \\
\text { enraizados no negro americano que } \\
\text { perdura, muitas vezes, até hoje. }\end{array}$ \\
\hline
\end{tabular}

Tabela 5 - Discursos Socioideológicos no Conto (segunda questão)

\begin{tabular}{|l|l|}
\hline Pré-teste & Pós-teste \\
\hline $\begin{array}{l}\text { O texto demonstra, por meio das } \\
\text { experiências do garoto, um contexto } \\
\text { racista. }\end{array}$ & $\begin{array}{l}\text { O texto refrata discursos que se } \\
\text { relacionam a tensões que, apesar de não } \\
\text { serem recentes, ecoam fortemente na } \\
\text { sociedade até hoje. }\end{array}$ \\
\hline
\end{tabular}

$\mathrm{Na}$ avaliação das sete atividades de análise dos alunos, percebemos que eles fizeram uma nomeação mais específica de diferentes discursos encontrados no conto, tais como o discurso machista, o discurso de superioridade branca (reproduzido e internalizado pelas crianças), o discurso religioso de aprisionamento, o discurso do branco que animaliza o negro, afetando a construção da identidade dos afro-americanos, que se encontravam sempre vivendo tensões culturais e relações de domínio herdadas historicamente. Dessa forma, os negros eram condicionados a viver e a pensar como seres inferiores, tanto em aspectos físicos quanto morais, sendo necessário que se determinasse como deveriam agir e se comportar (NOTT, 2005).

Além disso, identificamos que a compreensão do aluno estava embasada na teoria estudada, tendo em vista a apropriação que fizeram de termos-chave em suas respostas. Não raramente, os alunos mencionaram a noção de vozes sociais, como observamos na Tab. 4: "[a]lguns aspectos encontrados no conto" passam a ser "[a]s vozes sociais que estão presentes no texto". Há aqui a apropriação da noção bakhtiniana de $v o z$, encontrada na prosa ficcional (romance), entendida como um "um fenômeno pluriestilístico, heterodiscursivo e heterovocal" (BAKHTIN, 2015, p. 27). É importante lembrarmos que, para alguns leitores de Bakhtin, como Shukman (1983), a noção de voz está diretamente relacionada a quem está falando no texto; no entanto, para outros como Emerson (1984, p. 36), voz é uma "posição semântica, um ponto de vista sobre o mundo" (grifo do autor) ${ }^{13}$. Nesse sentido, é imperiosa a menção de que o aluno, ao se

\footnotetext{
${ }^{13}$ Texto original: "a semantic position, a point of view on the world".
} 


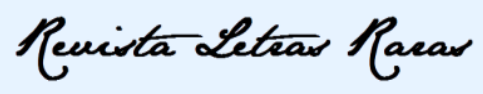

ISSN: 2317-2347 - v. 7, n. 1 (2018)

apropriar da teoria nesse processo de compreensão ativo-dialógica, assume o termo voz como voz social.

Por fim, na Tab. 5, vemos a mudança do verbo demonstrar para refratar: de "[o] texto demonstra $[\ldots]$ um contexto racista" para "[o] texto refrata discursos $[\ldots]$ ". A ideia de refratar, conforme explicado por Faraco (2009) [ver nota de rodapé 3], é um conceito bastante caro para os estudos do Círculo, pois evoca a subjetividade da representação do signo e, por conseguinte, da representação literária. Percebemos, portanto, que o aluno, ao assimilar a palavra do outro (a noção de refratar), participa da construção da sua própria formação discursiva, que está relacionada com o objetivo deste estudo. Para Bakhtin (2015, p. 135), “o processo de formação ideológica do homem é um processo de assimilação seletiva das palavras dos outros".

A assimilação e internalização de conceitos-chave da teoria (discurso do outro) apontam para a compreensão do aluno não apenas do enredo do conto, mas do diálogo entre conceitos estudados durante o minicurso e discursos socioideológicos suscitados pelo texto literário, resultando em enunciados (respostas dos alunos) que apresentam o seu posicionamento axiológico diante do texto (conto) e do mundo (contexto). Como diria Bakhtin (2015, p. 135-136), “[a]qui, o discurso do outro já não atua como informação, instrução, regras, modelos, etc.; ele procura determinar os próprios fundamentos da nossa relação ideológica com o mundo [...]".

\section{Considerações finais}

Este artigo teve o objetivo de contribuir para a discussão sobre o ensino de literatura estrangeira no Brasil. Para tal, por meio de um estudo empírico com alunos iniciantes do curso de Letras-Inglês, buscou investigar as contribuições da teoria dialógica do Círculo para esse processo de estudo/análise do texto literário em língua inglesa.

Concentrados no processo de compreensão ativo-dialógica (BAKHTIN, 2017b), buscamos gerar dados a partir de uma atividade de análise do conto The childhood of Jimmy (HUGHES, 1996) feita antes (pré-teste) e depois (pós-teste) do estudo do ensaio 


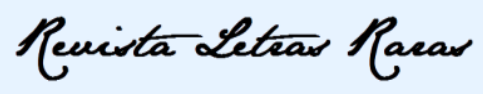

ISSN: $2317-2347$ - v. 7, n. 1 (2018)

$O$ discurso no romance (BAKHTIN, 2015) durante o minicurso $A$ representação do negro em contos da literatura afro-americana: uma perspectiva dialógica.

Percebemos, na análise do pós-teste, em comparação com o pré-teste, que os alunos passaram a relacionar o enredo do conto de forma mais pontual com os discursos sociohistóricos nele presentes, reconhecendo que o enredo representa os universos ideológicos das personagens (BAKHTIN, 2015). Ademais, identificamos que o processo de compreensão ativo-ideológico dos participantes do minicurso abrangeu a compreensão do contexto histórico concreto do conto, da materialidade da obra literária, ou seja, da percepção da palavra em sua natureza linguística e socioideológica, e da própria teoria, por meio da assimilação da palavra do outro (teoria), que "[g]anha um significado mais profundo e substancial [...] no processo de formação ideológica do homem" (BAKHTIN, 2015, p. 135).

Por fim, gostaríamos de citar Cereja (2005), em sua proposta dialógica para o trabalho com literatura (de língua materna) no ensino médio. Segundo o autor,

O ensino de literatura no ensino médio deve, a nosso ver, estar comprometido, primeiramente, com o desenvolvimento de habilidades de leitura, a fim de que o aluno se transforme num leitor de textos literários competente. Além disso, como é a um só tempo linguagem, discurso e objeto artístico, a literatura deve ser tomada tanto em sua dimensão comunicativo-interativa, dialógica e estética, quanto em sua dimensão histórica, social e ideológica. (CEREJA, 2005, p. 198).

Com base nessa citação, podemos declarar, também, que o ensino de literatura estrangeira (de língua inglesa) no ensino superior deve estar comprometido com a compreensão dos alunos de textos literários em língua inglesa, ajudando-os a se tornarem leitores respondentes (que respondem aos textos de forma ativo-dialógica), compreendendo a natureza linguístico-artística do objeto literário e a sua dimensão socioideológica de enunciado-elo. Além disso, nesse processo de compreensão da literatura, que é "parte inseparável da cultura" (BAKHTIN, 2017a, p. 11), o leitor/analista de uma obra estrangeira passa a estabelecer uma relação dialógica entre culturas (nacional e estrangeira), que "não se fundem, nem se confundem; cada uma mantém a sua unidade e a sua integridade aberta, mas elas se enriquecem mutuamente" 


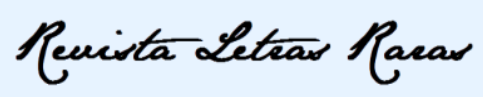

ISSN: 2317-2347 - v. 7, n. 1 (2018)

(BAKHTIN, 2017a, p. 19). É, portanto, esse enriquecimento mútuo que a compreensão ativo-dialógica da uma obra afro-americana proporciona ao aluno brasileiro de Letras.

\section{REFERÊNCIAS}

ARAN, P. Nuevo diccionario de la teoria de Mijaíl Bajtín. Córdoba: Ferreyra Editor, 2006.

BAKHTIN, M. O problema do conteúdo, do material e da forma na criação literária. In: BAKHTIN, M. Questões de literatura e de estética: a teoria do romance. Trad. Aurora F. Bernardini et al. 7. ed. São Paulo: Hucitec, 2014, p. 13-70

BAKHTIN, M. O discurso no romance. In: BAKHTIN, M. Teoria do romance I: a estilística. Tradução, prefácio, notas e glossário de Paulo Bezerra. São Paulo: Editora 34, 2015, p. 19-241.

BAKHTIN, M. Os gêneros do discurso. In: BAKHTIN, M. Os gêneros do discurso. Organização, tradução, posfácio e notas de Paulo Bezerra. São Paulo: Editora 34, 2016, p. 11-69.

BAKHTIN, M. A ciência da literatura hoje (Resposta a uma pergunta da revista Novi Mir). In: Notas sobre literatura, cultura e ciência humanas. Organização, tradução, posfácio e notas de Paulo Bezerra. São Paulo: Editora 34, 2017a, p. 9-19.

BAKHTIN, M. Por uma metodologia das ciências humanas. In: BAKHTIN, M. Notas sobre literatura, cultura e ciência humanas. Organização, tradução, posfácio e notas de Paulo Bezerra. São Paulo: Editora 34, 2017b, p. 57-79.

BAKHTIN, M. Fragmentos dos anos 1970-1971. In: BAKHTIN, M. Notas sobre literatura, cultura e ciência humanas. Organização, tradução, posfácio e notas de Paulo Bezerra. São Paulo: Editora 34, 2017c, p. 21-56.

BANKOLE, K. Negro. In: ASANTE, M.; MAZAMA, A. (Eds.). Encyclopedia of Black Studies. Thousand Oaks, California: Sage Publications, Inc., 2005, p. 370-371.

BEZERRA, P. Bakhtin: remate final. In: BAKHTIN, M. Notas sobre literatura, cultura e ciência humanas. Organização, tradução, posfácio e notas de Paulo Bezerra. São Paulo: Editora 34, 2017, p. 81-96.

BRAIT, B.; CAMPOS, M. I. Da Rússia czarista à web. In: BRAIT, B. (Org.). Bakhtin e o Círculo. São Paulo: Contexto, 2009, p. 15-30.

CEREJA, W. Ensino de literatura: uma proposta dialógica para o trabalho com literatura. São Paulo: Atual, 2005.

DUDALSKI, S. O ensino da dramaturgia shakespeariana no Brasil: realidade e perspectivas. 2007. 291f. Tese (Doutorado em Estudos Linguísticos e Literários em Inglês) - Faculdade de Filosofia, Letras e Ciências Humanas, Universidade de São Paulo, São Paulo, 2007. 


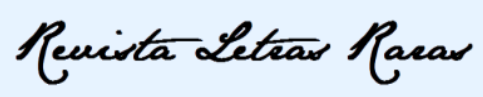

ISSN: 2317-2347 - v. 7, n. 1 (2018)

EMERSON, C. Editor's Preface. BAKHTIN, M. Problems of Dostoevsky's Poetics. Editado e traduzido por Caryl Emerson. Minneapolis, MN: University of Minnesota Press, 1984, p. 29-43.

FARACO, C. A. Aspectos do pensamento estético de Bakhtin e seus pares. Letras de hoje, v. 46, n. 1, p. 21-26, 2011. Disponível em: [http://revistaseletronicas.pucrs.br/ojs/index.php /fale/article/view/9217/6367]. Acesso em: 01 dez. 2017.

FARACO, C. A. Linguagem \& diálogo: as ideias linguísticas do Círculo de Bakhtin. São Paulo: Parábola Editorial, 2009.

FRANKLIN, J. H.; MOSS JR., A. A. From Slavery to freedom: a history of African Americans. 7. ed. New York: McGraw-Hill, Inc., 1994.

HUGHES, Langston. Langston Hughes: short stories. Edited by Sullivan Harper. Nova York: Hill And Wang, 1996.

KLARMAN, M. From Jim Crow to civil rights: the Supreme Court and the struggle for racial equality. New York: Oxford University Press, 2004.

MEDVIÉDEV, P. O método formal nos estudos literários: introdução crítica a uma poética sociológica. Trad. Sheila Camargo Grillo e Ekaterina Vólkova Américo. São Paulo: Contexto, 2012.

MELO JR., O. O ensino de literatura em língua inglesa no curso de Letras: uma abordagem dialógico-pragmática. Bakhtiniana. Revista de Estudos do Discurso, v. 10, n. 1, p. 87-103, 2015. Disponível em: [http://dx.doi.org/10.1590/2176-457320692]. Acesso em: 01 dez. 2017.

MELO JR., O. O ensino dialógico de literatura em língua inglesa no curso de Letras: diferentes espaços. Linguagem \& Ensino, v.19, n.1, p. 145-171, 2016a. Disponível em: [http://www.rle.ucpel.tche.br/index.php/rle/article/view/1456/924]. Acesso em: 06 dez. 2017.

MELO JR., O. Língua e Literatura em diálogo: uma análise dialógica de El Sonavabitche de Gloria Anzaldúa e suas implicações. Calidoscópio, v. 14, n. 1, p. 145158, 2016b. Disponível em: [http://doi.org/10.4013/cld.2016.141.13]. Acesso em: 06 dez. 2017.

NOTT, J. C.; GIDDON, G. R. Types of mankind: or, Ethnological researches. Ann Arbor: University Of Michigan Library, 2005. Disponível em: [http://name.umdl.umich.edu/AJA7398.0001.001]. Acesso em: 18 jun. 2017.

PACHECO, J. F. O problema do racismo nos Estados Unidos. Curitiba: Imprensa da UFPR, 1983. 157 p.

PERRONE-MOISÉS, L. O ensino da literatura. In: PERRONE-MOISÉS, L. Mutações da literatura no século XXI. São Paulo: Companhia das Letras, 2016, p. 70-82.

SANTOS, E. P. As minorias na literatura norte-americana. Textura, v. 3, n. 4, p. 3-12, 2001. Disponível em: [http://www.periodicos.ulbra.br/index.php/txra/article/view/690/ 501]. Acesso em: 20 jun. 2017. 


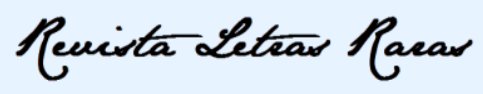

ISSN: 2317-2347 - v. 7, n. 1 (2018)

SHUKMAN, Ann. Glossary of key terms. In: SHUKMAN, Ann (Ed.). Bakhtin school papers. Oxford: RPT Publications, 1983.

VOLÓCHINOV, V. Marxismo e filosofia da linguagem: problemas fundamentais do método sociológico na ciência da linguagem. Tradução, notas e glossário de Sheila Grillo e Ekaterina Vólkova Américo. São Paulo: Editora 34, 2017.

VOLOŠINOV, V. La parola nella vita e la parola nella poesia. In: PONZIO, A. (Org.). Michail Bachtin e il suo Circolo: opere 1919-1930. Trad. Augusto Ponzio e Luciano Ponzio. Milano: Bompiani/RCS Libri S.p.A., 2014a, p. 271-333.

VOLOŠINOV, V. Che cos'è il linguaggio? In: PONZIO, A. (Org.). Michail Bachtin e il suo Circolo: opere 1919-1930. Trad. Augusto Ponzio e Luciano Ponzio. Milano: Bompiani/RCS Libri S.p.A., 2014b, p. 1843-1891.

VOLOSHINOV, V. Discourse in life and discourse in poetry: questions of sociological poetics. Trad. John Richmond. In: SHUKMAN, Ann (Ed.). Bakhtin school papers. Oxford: RPT Publications, 1983a, p. 5-29.

VOLOSHINOV, V. The word and its social function. Trad. Joe Andrew. In: SHUKMAN, Ann (Ed.). Bakhtin school papers. Oxford: RPT Publications, 1983b, p. 139-152.

VOLOSHINOV, V. The construction of the utterance. Trad. Noel Owen. In: SHUKMAN, Ann (Ed.). Bakhtin school papers. Oxford: RPT Publications, 1983c, p. 115-137.

VOLOSHINOV, V. What is language? Trad. Noel Owen. In: SHUKMAN, Ann (Ed.). Bakhtin school papers. Oxford: RPT Publications, 1983d, p. 93-113.

Recebimento: 05/01/2018

Aceite: $26 / 02 / 2018$ 